\title{
A Method for Studying the Effects of Neurochemicals on Long-Term Compensation in Unilaterally Labyrinthectomized Rats
}

\author{
Lars Andersson, Mats Ulfendahl, and Richard Tham \\ Departments of Biomedical Engineering and Otorhinolaryngology, Faculty of Health Sciences, \\ University Hospital S 58183 Linköping, and Departments of Physiology and Pharmacology, \\ Karolinska Institute, S171 77 Stockholm, Sweden
}

\section{SUMMARY}

A new method has been developed to study the influence of drugs and toxicants on longterm recovery of dynamics in the horizontal vestibulo-ocular reflex of the rat after hemilabyrinthectomy (HL). HL was performed by injecting sodium arsanilate into the middle ear. The lesion was confirmed by histology. Eye movements elicited by sinusoidal vestibular stimulation, in both light and darkness, were recorded by a search-coil technique and then analyzed by a computer program created with virtual instrument soft-ware, which calculated the gain of the slow-phase velocity (SPV) and the saccades para-meters (frequency, amplitude, and peak velocity) to the lesioned side and to the intact side separately. During the 2-10 week period after $H L$, repeated analysis of the spontaneous long-term recovery of such parameters revealed a slight but significant reduction of the post-HL asymmetry between SPV gain to the lesioned side and to the intact side. During the follow-up period, a post-HL increase of the phase lead remained unchanged. The reduced number of saccades/min was not completely restored. To test the usefulness of the experimental model for neurochemical investigation of such adaptation, we administered baclofen and toluene to rats 8-12 wk after hemilabyrinthectomy. Baclofen, a specific GABA $_{B}$ agonist, immediately restored the

\footnotetext{
Reprint address:

Dr. Richard Tham

Department of Otorhinolaryngology

Faculty of Health Sciences,

University Hospital S 58183 Linköping, Sweden
}

symmetry of SPV gain. By contrast, toluene, which has some effects on the central vestibular system that are related to $\mathrm{GABA}_{B}$ transmission, aggravated the asymmetry in both the SPV gain and the number of saccades. We suggest that the experimental model would be useful for studying neurochemical mechanisms in vestibular adaptation processes.

\section{KEY WORDS}

eye movements, vestibular compensation sinusoidal stimulation, virtual instrument, baclofen, toluene

\section{INTRODUCTION}

The interaction between the vestibulo-oculomotor reflex elicited by the vestibular labyrinthine hair cells, and the optokinetic reflex elicited by a retinal slip signal, acts to stabilize the retinal image by providing proper signals to the eye muscles. The high degree of adaptability of the right/left visual and right/left vestibular input system, either after lesions or during sustained conflicting visualvestibular signals, is well known. Therefore, the vestibular system can be used as a model to study learning and post-lesional plasticity in the central nervous system (for reviews see $/ 3,7 /$ ).

The purpose of the present investigation was to develop an experimental in vivo model that can be used to study how different toxic and pharmacological substances promote, inhibit, or reverse the long-term adaptation after hemilabyrinthectomy (HL). The rat is a suitable species for such studies because the combination of high availability and low costs enables a large series of experiments. Several other requirements must be fulfilled, however. 
Because the procedure of $\mathrm{HL}$ must be rapid and easy to execute, we chose to perform a chemical $\mathrm{HL}$. We then followed the adaptation process by estimating the post-lesional asymmetry of nystagmus, which was elicited by oscillatory vestibular stimulation on a turntable. As recordings of eye movements must be easy to perform, we used a search coil method that does not require surgical implantation of the coil. The procedure for analyzing eye movements must be fast and easily comprehensible, so we applied 'virtual instrument' software for computerizing the analysis. The program must calculate separately the gain (the slow-phase velocity [SPV] of nystagmus divided by the velocity of the turntable) achieved during stimulation toward both the intact and the lesioned labyrinth.

Gamma-Aminobutyric acid (GABA) is the main inhibitory neurotransmitter in the central vestibular system. To test the experimental setup, we investigated the effect of baclofen, a $G_{A B A}$ agonist, and toluene, which reportedly causes some vestibular disturbances that are related to GABA transmission /13/.

\section{MATERIALS AND METHODS}

\section{Animals}

Pigmented rats (DA-HAN) aged 4-9 months and weighing 175-350 g each were used in this study. Nine animals were equipped with a fixation device (see below) and tested before HL, 2 wk after $\mathrm{HL}$, and then once weekly until the fixation device came off (5-8 weeks after HL). Another 10 animals were equipped with fixation nuts at different times (4-9 weeks) after $\mathrm{HL}$ and then examined up to 10 weeks after $\mathrm{HL}$ or until the fixation device fell off. For the pharmacological tests, 24 rats were hemilabyrinthectomized as described below.

\section{Recording of eye movements}

For proper fixation, the heads of the animals were equipped with a metal nut that was attached to the bone by means of dental cement and stainless steel screws. During the tests, the rats were restrained within a plastic frame with sidewalls for the body, and a screw was inserted into the nut to immobilize the head. The frame was placed in a plastic chamber on a turntable that was surrounded by a cylindrical white screen onto which a stillstanding illuminated pattern of stripes could be projected (see $/ 14,15 /$ for details). A computer (Macintosh Iici) controlled the movements of the turntable. Recordings of horizontal eye movements were made by a magnetic search coil system /10/ (for details of the application see /14/). The eye position signal and the eye velocity signal, obtained by differention of the position signal, were recorded. The eye position signal and the stimulation velocity signal were fed to an analogue-digital (A/D) converter board (with a sampling rate of 100 $\mathrm{Hz}$ for each channel) connected to the computer for digital storage and off-line data analysis.

\section{Stimulation and test program}

Sinusoidal oscillations were performed during a period of 2 minutes at $0.05,0.2$, and $0.8 \mathrm{~Hz}$, in either darkness or an illuminated, stationery environment. The respective peak angular velocities of the turntable were 20, 90, and $90 \% \mathrm{sec}$. Each frequency was tested 2-4 times in a balanced order, alternately in darkness and light. In the baclofen and toluene experiments, oscillatory stimulation was performed only in darkness at 0.2 and $0.8 \mathrm{~Hz}$.

\section{Analysis of eye movements}

We created a computer program for off-line computation of the eye movement data by using virtual instrument (VI) technology (LabVIEW 2, National Instruments). The software uses graphical modules, simulating a physical device, referred to as a VI. The VI comprises two parts: A front panel, the graphical user interface, and a flowchart, where the function of the instrument is determined by wiring of graphical symbols. The collected eye movements signals were analyzed in blocks of $40 \mathrm{~s}$ $(0.05 \mathrm{~Hz})$ or $20 \mathrm{~s}(0.2$ and $0.8 \mathrm{~Hz})$. To obtain steady-state values, the position of the block within a recording was manually selected from the second half of the 2-min stimulation period.

The analysis of eye movements from $\mathrm{HL}$ animals rotated at $0.2 \mathrm{~Hz}$ in darkness is illustrated in Fig. 1 . The upper part of the figure shows the turntable 

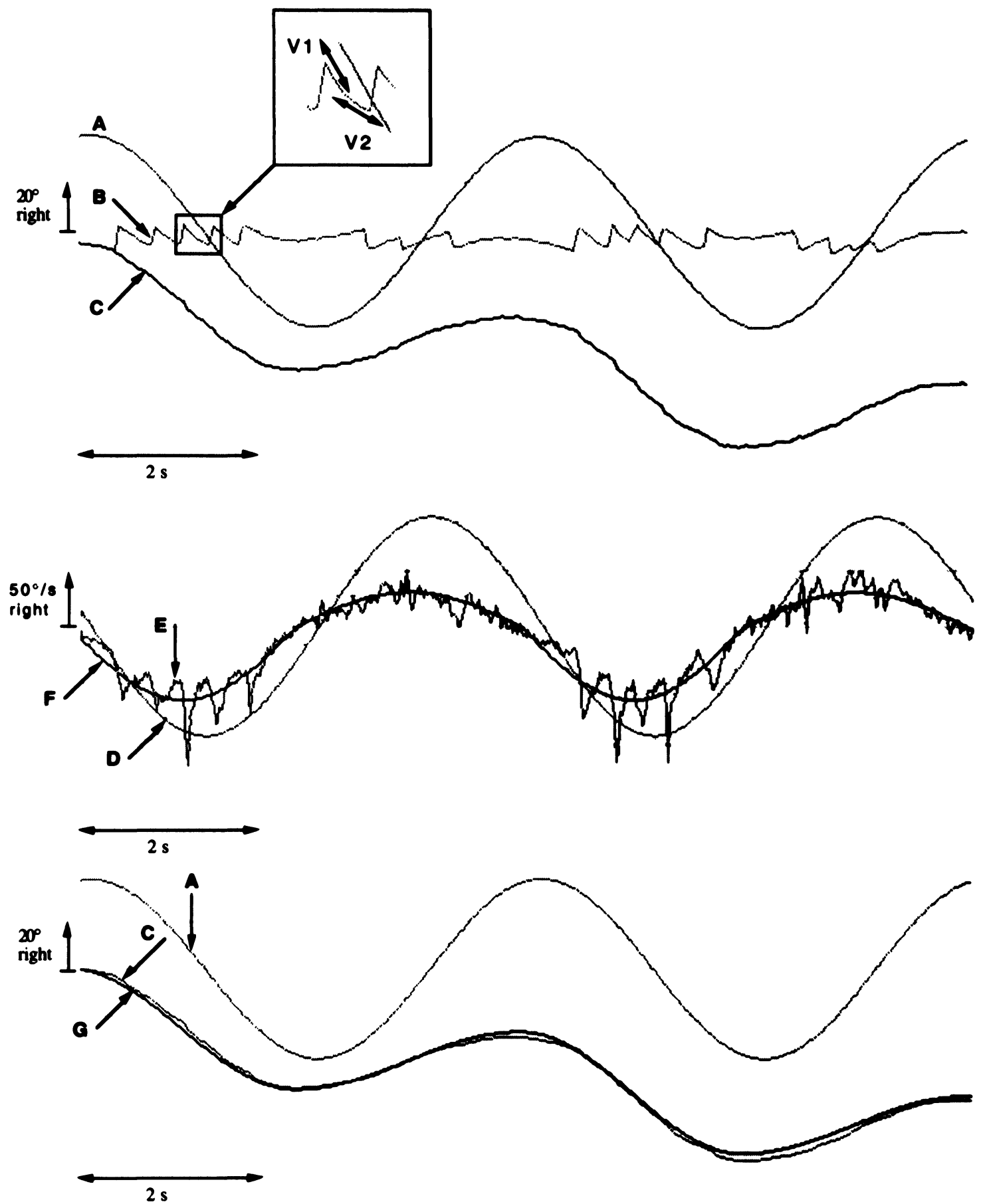

Fig. 1. HL rat: Analysis of nystagmus elicited by sinusoidal oscillation $(0.2 \mathrm{~Hz}$, peak velocity $90 \% \mathrm{sec})$ in darkness. For explanation see text. 
position (A) and the eye position (B) signals. Initially, the saccades were removed and replaced with second-order polynomials, providing continous curves regarding both position and velocity. This procedure resulted in the position signal $\mathrm{C}$. A side difference is observed as a linear trend in the position signal. The total number of saccades were counted, and their amplitudes and peak velocities were calculated. For analysis of phase and separated left/right gain, the corresponding velocity signal was calculated as seen in the middle part of Fig. 1, where $\mathrm{D}$ is the turntable velocity and $\mathrm{E}$ is the eye velocity. Using an asymmetrical sinus signal with different amplitudes for both half periods, we applied a least-squares best-fit curve algorithm to signal $\mathrm{E}$, resulting in $\mathrm{F}$. The reliability of the calculated signal is demonstrated when signal F is transformed back to the corresponding position signal (G) and compared with the original position signal (C). The reconstructed velocity signal (F) was used to calculate the left/right gain and phase values.

\section{Chemical labyrinthectomy}

The animals were given a short-lasting (30-60 sec) anesthesia by halothane inhalation. Under microscope observation, $0.1-0.2 \mathrm{~mL}$ of a solution of sodium arsanilate (100 mg/mL in isotonic saline) was injected through the ventral part of the tympanic membrane $/ 2 /$.

\section{Administration of toluene and baclofen}

Twenty-four animals were labyrinthectomized 812 weeks before the experiments. Ten of these rats were given intramuscular injections $(3 \mathrm{mg} / \mathrm{kg}$ body weight) of baclofen (Ciba Geigy, racemic mixture). All animals were examined in the vestibular test program both before and after drug administration. In control experiments, nine animals received an injection of $0.9 \%$ sodium chloride each between the two test sessions. Fourteen animals were exposed to toluene. The equipment on the turntable, including the fixation device and search coil system, was enclosed in a transparent chamber. Compressed air $(10 \mathrm{~L} / \mathrm{min})$ was lead to the chamber through an adjustable evaporator supplied with toluene (Merck, FRG). The concentration of solvent in the chamber was measured by gas chromatography /15/. The mean level of toluene was $1950 \mathrm{ppm}( \pm 6 \%)$. After the vestibular test program had been performed once, the exposure was started, and 15 minutes later, the test program was carried out again during continuous exposure.

\section{Histology}

To confirm the destruction of the peripheral vestibular organs, we examined the temporal bones of seven animals $12-14 \mathrm{wk}$ after $\mathrm{HL}$. The rats were first anesthetized (chloral hydrate, i.p.) and then decapitated. Both temporal bones were removed and transferred to cold fixative containing $2.5 \%$ glutaraldehyde and $2 \mathrm{mM}$ magnesium chloride in $0.1 \mathrm{M}$ phosphate buffer ( $\mathrm{pH} 7.2$ ). The inner ear was exposed, and the cristae were dissected out and kept at $4{ }^{\circ} \mathrm{C}$ in fixative until histological processing.

After post-fixation in osmium tetroxide and dehydration, the tissue was imbedded in epoxy resin. Selected regions were sectioned and stained with toluidine blue for light microscopy. The sections were observed using a Zeiss Axiovert microscope, and photographs were taken with a 35mm camera (Contax; Kodak T-max 100 film).

\section{Statistics}

The results of the tests performed before and 2 wk after $\mathrm{HL}$ were compared using the paired Student's t-test. The recovery over time from 2-10 wk after $\mathrm{HL}$ was evaluated by linear regression analysis. In the toluene and baclofen experiments, the results from the tests performed before and during exposure were compared using the paired Student's t-test. In all tests, a difference of $p<0.05$ was considered to be statistically significant $(*=p<0.05, * *=p<0.01, * * *=p<0.001)$.

\section{RESULTS}

\section{General behavior}

Two days after receiving the injection of arsanilate, all rats showed symptoms of unilateral vestibular loss. The head was tilted toward the lesioned side, and upon tactile or noise stimulation, the animals expressed a circling behavior toward the 
lesioned side. All had spontaneous nystagmus, but these static symptoms gradually disappeared over the next 10-14 days.

\section{Histology}

At the microscopic level, the ampullae from the labyrinthectomized ears already looked empty and shrunken when compared with the tissue from intact ears. When observing the sections in the light microscope, we found that the exposed cristae from the lesioned side were severely damaged, especially at the nerve fiber level (Fig. 2). The area inside the crista looked empty (Fig. 2b) and not homogeneously filled with nerve fibers and supporting structures as seen in the control tissue from the same animal (Fig. 2a). The loss of stroma made the damaged cristae appear thinner. Occasionally, the epithelial layer contained single hair cells, but such cells showed distinct signs of damage, especially at the apical poles (Fig. 2c). The cuticular plates were bulging into the endolymphatic space. The location of surviving hair cells seemed to be correlated to the presence of remaining nerve fibers. In most animals, however, no hair cells at all were found.

\section{Vestibular dynamic tests}

Generally, the results from tests at $0.05 \mathrm{~Hz}$ were highly variable and depended on the alertness of the rat, whereas the results at 0.2 and $0.8 \mathrm{~Hz}$ were more constant. Whether tested in light or in darkness (Figs. 3 and 4), the gain to the intact side $2 \mathrm{wk}$ after $\mathrm{HL}$ was unchanged in most tests compared with the gain before HL. The gain to the lesioned side, which was markedly reduced at all frequencies tested, indicated that an asymmetry, defined as the difference between the gain to the intact and to the lesioned sides, had developed. During repeated tests from the 2nd until the 10th week, the gain to the lesioned side was slightly but significantly restored at 0.2 and $0.8 \mathrm{~Hz}$ in both light and darkness, indicating a decrease in asymmetry. HL caused a slight increase of the phase lead at 0.2 and $0.8 \mathrm{~Hz}$, as demonstrated 2 wk after $\mathrm{HL}$ (Fig. 4). The increase was permanent during the next 8 weeks. After HL, the number of saccades per minute was reduced, in the direction to both the lesioned and the intact sides, except at $0.5 \mathrm{~Hz}$ in the light (Fig. 4). The number was reduced more to the lesioned side.
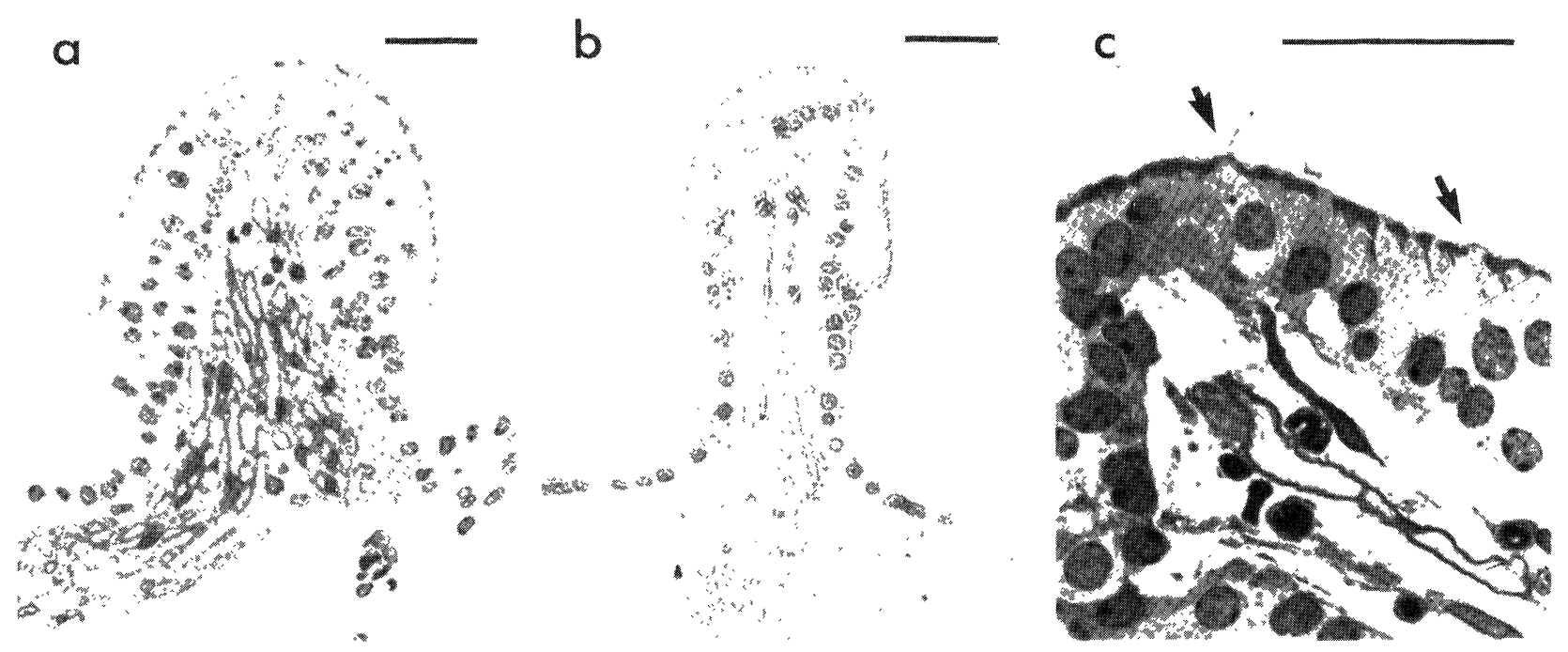

Fig. 2. HL animal: Light micrographs of sections from cristae ampullares. (a) The crista from the control side. (b) The crista from the lesioned side. Note the empty appearance of the stroma beneath the epithelial layer. (c) Higher magnification of a section adjacent to that shown in (b). A few hair cells (arrows) remain in the sensory epithelium. All scale bars $=30 \mu \mathrm{m}$. 


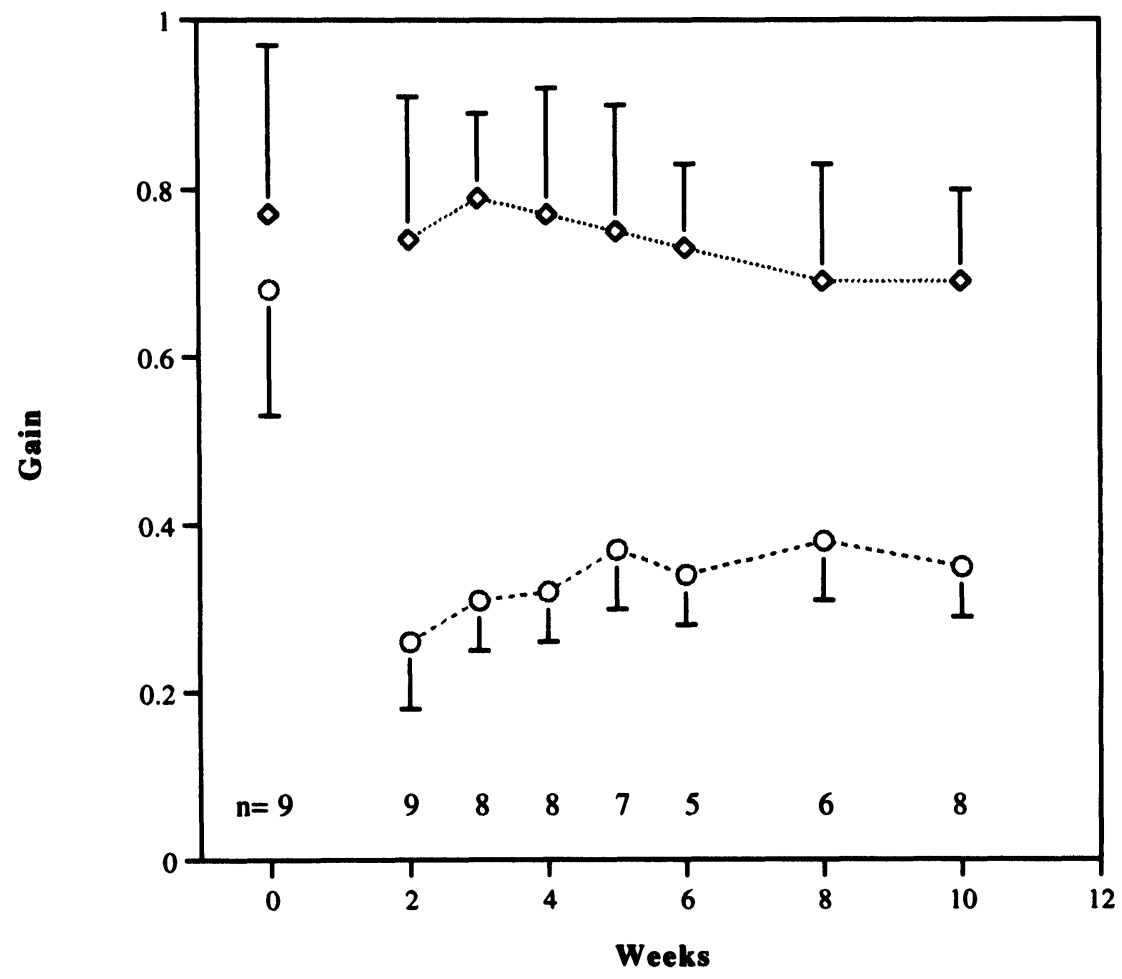

Fig. 3. Mean gain of the slow phase velocity (SPV) recorded during sinusoidal oscillation $(0.2 \mathrm{~Hz}$, peak velocity $90 \% \mathrm{sec})$ in darkness before (time $=0$ ) and after $\mathrm{HL} . \mathrm{O} \cdots \mathrm{O}=$ gain to the lesioned side; $\diamond \cdots \diamond$ gain to the intact side. Vertical lines indicate $1 \mathrm{SD}$.

No change occurred during the follow-up period at 0.05 and $0.2 \mathrm{~Hz}$. At $0.8 \mathrm{~Hz}$, the number to the lesioned side again increased (Fig. 4). At some frequencies, $\mathrm{HL}$ also caused a slight reduction of the amplitude and maximal velocity of the saccades to the lesioned side, which was restored during the long-term period.

\section{Effects of toluene and baclofen}

Figure 5 shows that the administration of baclofen caused an immediate re-establishment of the symmetry of SPV gain during oscillation, performed by both a decrease of the gain to the intact side and an increase to the lesioned side. The drug caused no changes of the number of saccades/min but rather a significant decrease of the average amplitude, both the lesioned and to the intact side. Exposing partly compensated HL rats to toluene caused an increase of the SPV gain asymmetry during oscillation, which was mainly caused by an increase of the gain to the intact side. The difference between the number of saccades to the intact and lesioned side increased (from 18 to 35 and from 10 to $46 \mathrm{saccades} / \mathrm{min}$ at 0.2 and $0.8 \mathrm{~Hz}$, respectively), mainly depending on an increased number to the intact side but also depending on a decrease to the lesioned side at $0.8 \mathrm{~Hz}$.

Between the first and second test sessions in nine control experiments with the vehicle, no significant differences of asymmetry occurred. (At $0.2 \mathrm{~Hz}$ the mean gains to the intact and lesioned sides were 0.60/0.29 during the first test and $0.61 / 0.32$ during the second test. At $0.8 \mathrm{~Hz}$, the respective corresponding figures were $0.58 / 0.33$ and $0.61 / 0.35)$. Neither toluene nor baclofen caused any general behavioral effects, and spontaneous nystagmus did not develop. 

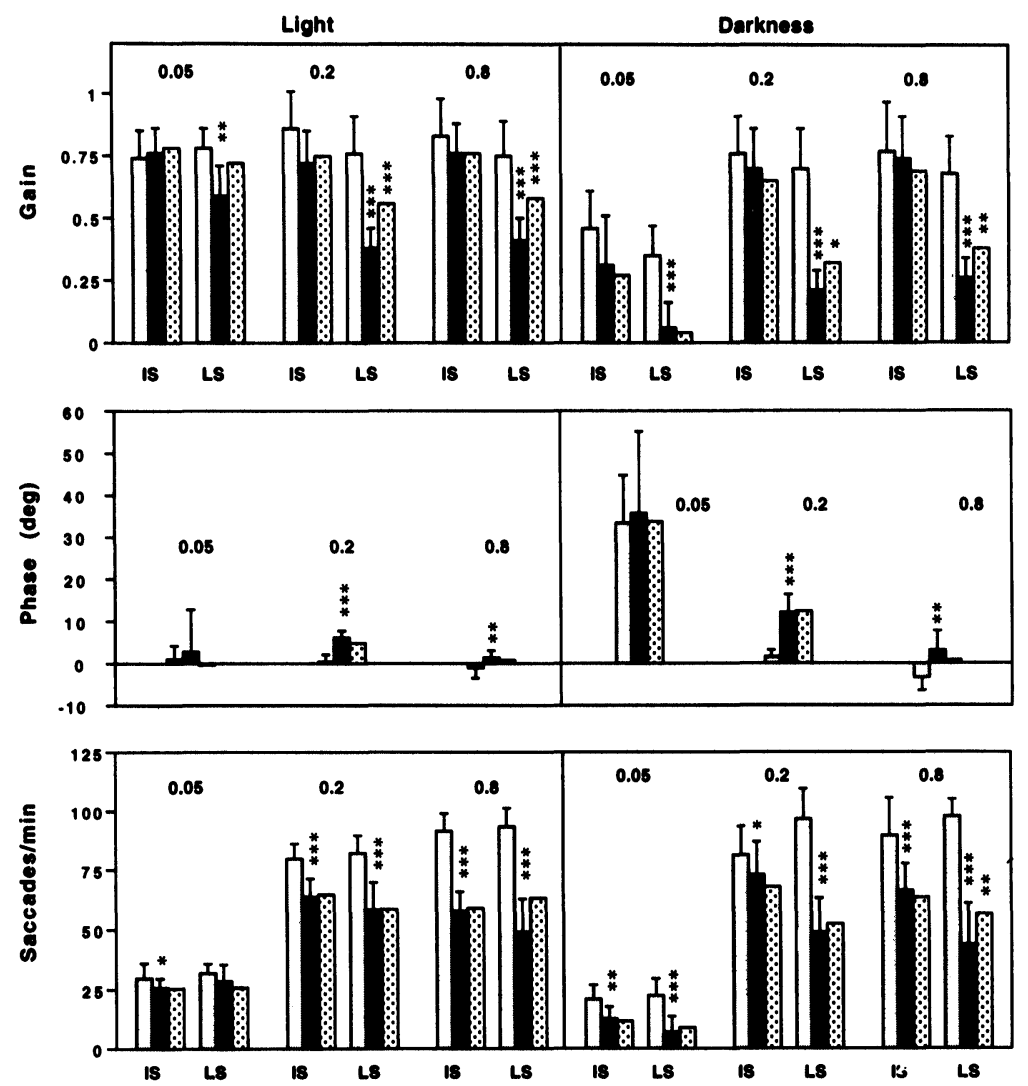

Fig. 4. Mean parameters of eye movements during sinusoidal oscillation at $0.05,0.2$, and $0.8 \mathrm{~Hz}$ before and after $\mathrm{HL}$. $\square=$ before $\mathrm{HL} ; \boldsymbol{\square}=2$ wk after HL; stars indicate significant changes compared with the tests before $\mathrm{HL}$ (paired t-test); : = $10 \mathrm{wk}$ after HL. The values are calculated from linear regression analysis of the test results at $2,3,4,5,6$, and 10 wk after HL. Stars indicate a significant slope of the simple regression line. IS = to intact side; LS to lesioned side. Vertical lines indicate 1 SD. See Fig. 3 for $\mathbf{n}$ values.

BACLOFEN

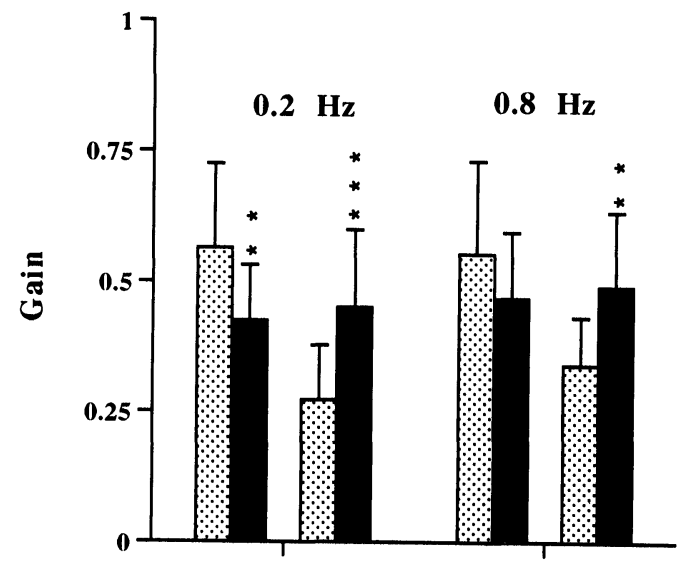

IS

LS

IS

LS

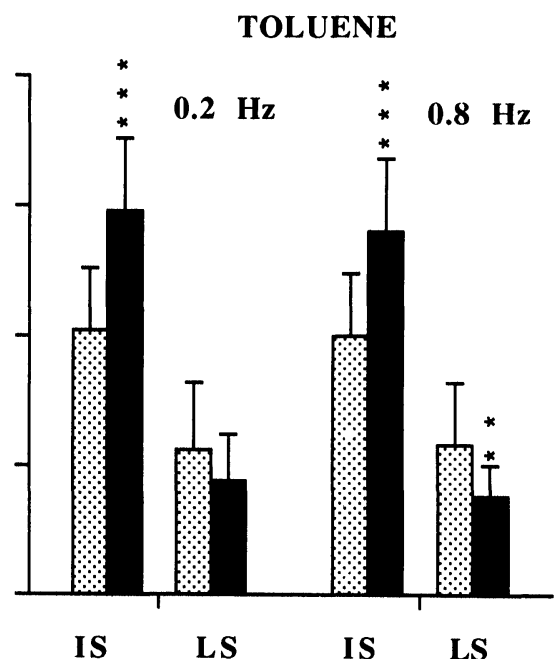

Fig. 5. Mean SPV gain before and after administration of baclofen (left, $n=10$ ) or toluene (right, $n=14)$ to $H L$ rats. $\%=$ before drug administration, = after drug administration. Stars indicate a significant change (paired t-test). IS = to intact side; LS to lesioned side. Vertical lines indicate $1 \mathrm{SD}$. 


\section{DISCUSSION}

Anniko and Wersäll /1,2/ demonstrated that systemic administration of arsanilate causes the degeneration of the cristae ampullares and the nerve terminals in the cochlea. The manifestation of symptoms of vestibular damage within $24 \mathrm{hr}$ after administration of arsanilate directly into the middle ear of rats has also been reported /11/. The results of the present study confirm that this procedure offers a rapid and easy way to perform a chemical hemilabyrinthectomy (HL) in the rat.

To analyze eye movements, we used the recently developed virtual instrument technique to create an automatic computer program. Compared with other programming languages, LabVIEW is quicker and easier to learn, and the graphical approach is more intuitive. Prototyping is fast and flexible because the programs can easily be modified.

Analysis of vestibular imbalance during sinusoidal stimulation offers special problems. Traditionally, the gain is measured by estimating the amplitude of the position signal by Fourier methods, after removing the saccades and the trend. A trend coefficient, reflecting right/left asymmetry, can then be estimated. We found, however, that for analyzing separate gains to the lesioned and to the intact side, the Fourier methods were not usable, partly because of the asymmetrical shape of the sinusoidal signal (C in Fig. 1) and partly because the initial SPV of a separate nystagmus beat (Fig. 1, V1) was often faster than the final velocity (Fig. 1, V2). Such variation was more evident during rotation to the intact than to the lesioned side. Such facts became obvious when the position signal was transformed to the corresponding velocity curve (E in Fig. 1). The reconstructed curve $F$ in Fig. 1 illustrates that the application of a least-squares best-fit curve algorithm, using asymmetric sinus signals having different amplitudes for its half periods, offers a reliable method for calculating gain. The total gain, as well as right and left gain, could be estimated from this curve. Regarding the total gain, a close agreement with the Fourier method was found in recordings with a small imbalance, whereas during larger asymmetries, the imperfection of the Fourier method was evident.

Vestibular compensation after $\mathrm{HL}$ has been investigated in guinea pigs $/ 18 /$, rabbits, cats, monkeys, and humans (reviewed in /17/). The process includes both the restoration of shortlasting static symptoms and long-lasting dynamic symptoms $/ 4 /$. In all species tested, recovery was rapid from the dramatic behavioral and oculomotor static deficits. In pigmented rats, we found that this period lasted up to about $10 \mathrm{~d}$ after chemical $\mathrm{HL}$. A partial recovery of dynamic deficits, apparent when the initial period of static symptoms subsides, seems to occur as well, even though the rate and the extent of the process may differ. The total SPV gain (both left and right gain, not separated) during sinusoidal stimulation slowly increases during this period of recovery. The asymmetry of gain and saccades, however, has been previously analyzed in detail in just a few investigations /18/.

In the present study, we focused the analysis on the recovery of long-lasting dynamic symptoms in rats, which has not yet been investigated. The capability of the newly created computer program to facilitate a separate rapid analysis of all parameters of eye movements to the intact and to the lesioned side provides a basis for studying dynamic symptoms.

We tested the applicability of the model for studying the influence of neurochemicals by administering baclofen or toluene to partially compensated $\mathrm{HL}$ animals. Baclofen, a specific $\mathrm{GABA}_{B}$ agonist, caused an immediate total compensation. In the central vestibular system, $\mathrm{GABA}_{\mathrm{B}}$ receptors are found on Purkinje cell dendrites and on parallel fibers in the molecular layer in the cerebellar cortex, as well as in the vestibular nuclei $/ 6,8 / \mathrm{GABA}_{\mathrm{B}}$ transmission has been suggested to have a general modulatory function and to cause neurotransmissional amplification through its inhibitory function /12/. The findings presented here may be in line with this suggestion and must be evaluated further.

By contrast, toluene caused an aggravated asymmetry of the SPV gain and the number of saccades to the intact and the lesioned side. Toluene has some specific effects on the central vestibular system /15/ that are related to GABA transmission /13/. Further experiments must be carried out to determine whether the effect of toluene on the vestibular system after $H L$ is related to $G_{A B A}$ transmission.

Current hypotheses on the mechanisms leading 
to vestibular compensation after $\mathrm{HL}$ are still rather speculative $/ 5,16,17 /$. The initial fast recovery of the static and postural symptoms is correlated with a partial recovery of the resting activity of the ipsilateral vestibular nuclei. Most studies of mechanisms have hitherto been focused on this stage. During the subsequent slower process of adaptation, it is evident that inputs from the visual and the somatosensory systems and from the intact contralateral labyrinth to the vestibular nuclei must be redefined to compensate for the loss of input from the lesioned labyrinth $/ 9 /$. Investigations analyzing how different neurochemical agents affect such adaptation will contribute new pieces to the final understanding of the process. The in vivo experimental model described here may prove to be one of several tools for such studies because it fulfills the following requirements, as outlined in the introductory section: (a) The procedure of $\mathrm{HL}$ is rapid and easy to execute; (b) the recordings of the eye movements are not only rapid and easy to perform but also easily comprehensible; and (c) the computer program calculates separate gains toward the intact and toward the lesioned labyrinth.

\section{ACKNOWLEDGMENTS}

This investigation was supported by a program project from the Swedish Work and Environmental Fund, grant no. 84-1291. The skillful technical assistance of Birgitta Eriksson is gratefully acknowledged.

\section{REFERENCES}

1. Anniko M, Wersäll J. Afferent and efferent nerve terrminal degeneration in the guinea-pig cochlea following Atoxyl administration. Acta Otolaryngologica 1976; 82: 325-336.

2. Anniko M, Wersäll J. Experimentally (ATOXYL) induced ampullar degeneration and damage to the maculae utriculi. Acta Otolaryngologica 1977; 83: 429-440.

3. Berthoz A, Melvill Jones G. Adaptive mechanisms in gaze control: Facts and theories. Reviews of Oculo- motor Research, Vol 1. Amsterdam: Elsevier, 1985.

4. Darlington C, Flohr H, Smith P. Molecular mechanisms of brainstem plasticity. Mol Neurobiol 1991; 5: 355-368.

5. Darlington C, Smith P. The recovery of static vestibular function following peripheral vestibular lesions in mammals: The intrinsic mechanism hypothesis. $\mathrm{J}$ Vestibular Res 1996; 6: 185-201.

6. De Waele $\mathrm{C}$, Mühlethaler $\mathrm{M}$, and Vidal PP. Neurochemistry of the central vestibular pathways. Brain Res Rev 1995; 20: 24-46.

7. Du Lac S, Raymond J, Sejnowski TJ, Lisberger SG. Learning and memory in the vestibulo-ocular reflex. Ann Rev Neurosci 1995; 18: 409-441.

8. Dutia MB, Johnston AR, McQueen DS. Tonic activity of rat medial vestibular nucleus neurones in vitro and its inhibition by GABA. Exp Brain Res 1992; 88: 466472.

9. Flohr N, Luneburg U. Role of NMDA receptors in lesion-induced plasticity. Archives Italiennes de Biologie 1993; 131: 173-190.

10. Kapser HJ, Hess BJM, Dieringer N. A precise and inexpensive magnetic search coil system for measuring eye and head movements in small laboratory animals. $\mathbf{J}$ Neuroscience 1987; 19: 115-124.

11. Kaufman G, Anderson J, Beitz A. Brainstem Fos expression following acute unilateral labyrinthectomy in the rat. NeuroReport 1992; 3: 829-832.

12. Mott $D$, Lewis $D$. The pharmacology and function of central $\mathrm{GABA}_{\mathrm{B}}$ receptors. Int Rev Neurobiol 1994; 36: 97-223.

13. Niklasson $\mathrm{M}$, Stengård $\mathrm{K}$, Tham $\mathrm{R}$. Are the effects of toluene on the vestibulo- and opto-ocular motor system inhibited by action of the GABA-B antagonist CGP 35348. Neurotox Teratol 1995; 17: 351-357.

14. Niklasson M, Tham R, Larsby B, Eriksson B. The influence of visual and somatosensory input on the vestibulo-oculomotor reflex of pigmented rats. J Vestibular Res 1990.91: 1: 251-262.

15. Niklasson M, Tham R, Larsby B, Eriksson B. Effects of toluene, styrene, trichloroethylene, and thrichloroethane on the vestibulo- and opto-ocular motor system in rats. Neurotox Teratol 1993; 15: 327-334.

16. Smith $P$, Darlington $C L$. Neurochemcial mechanisms of recovery from perpheral vestibular lesions (vestibular compensation). Brain Res Rev 1991; 16: 117-133.

17. Smith PF, Curthoys IS. Mechanisms of recovery following unilateral labyrinthectomy: A review. Brain Res Rev 1989; 14: 155-180.

18. Vibert $N$, deWaele C, Escudero M, Vidal P. The horizontal vestibulo-ocular reflex in the labyrinthectomized guinea pig. Exp Brain Res 1993; 97: 263-273. 

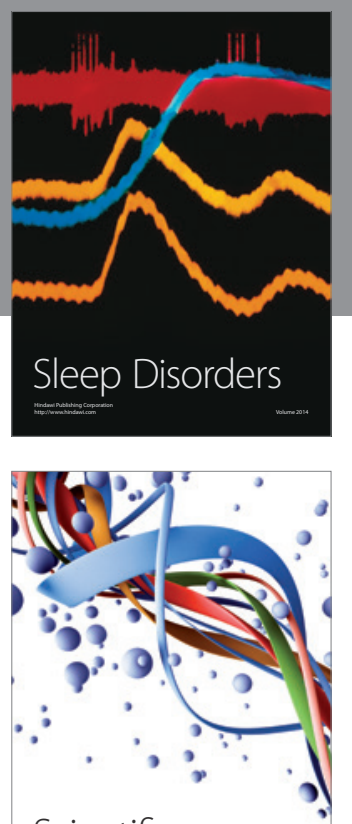

Scientifica
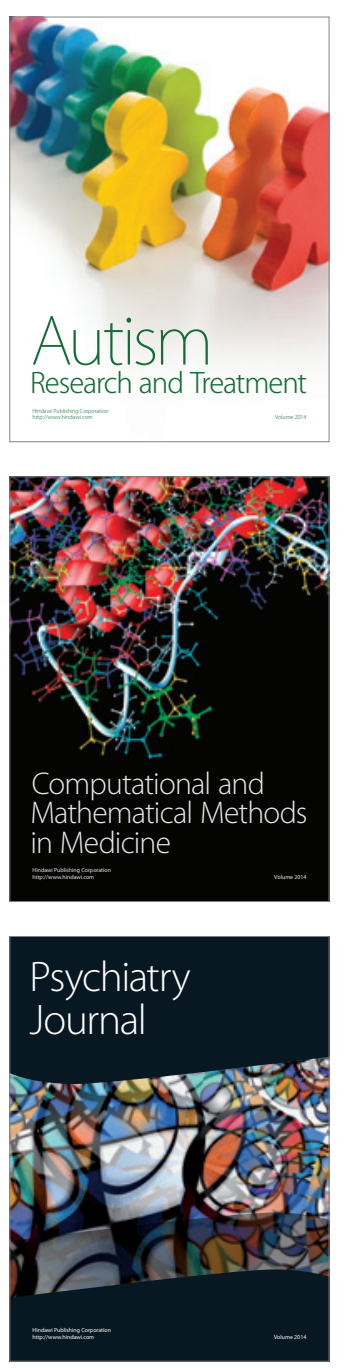
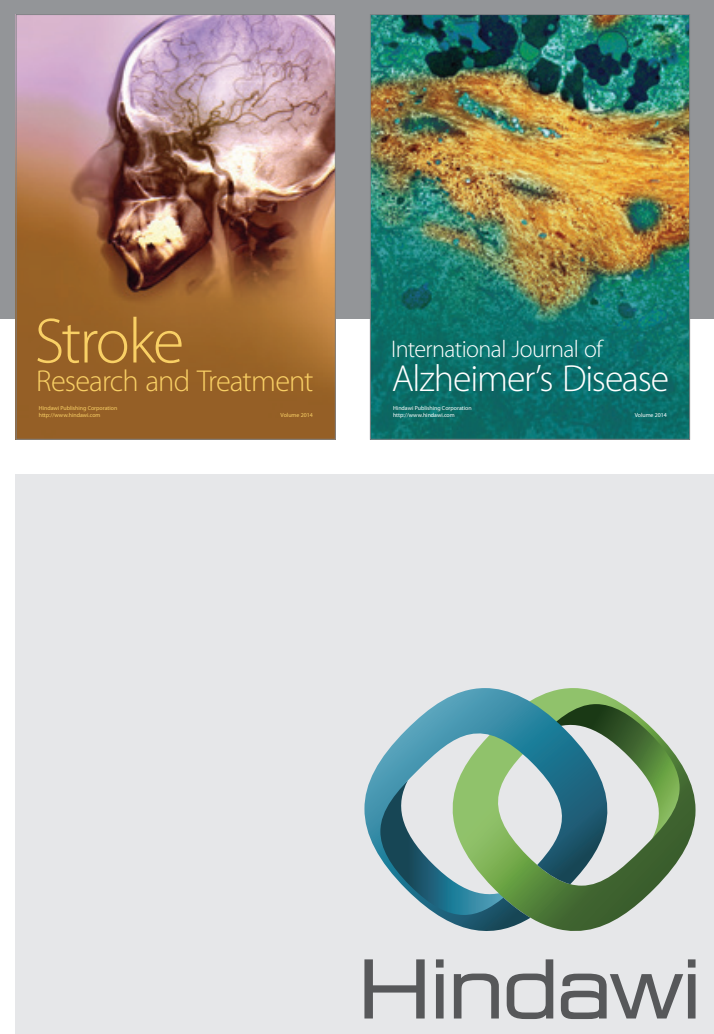

Submit your manuscripts at

http://www.hindawi.com
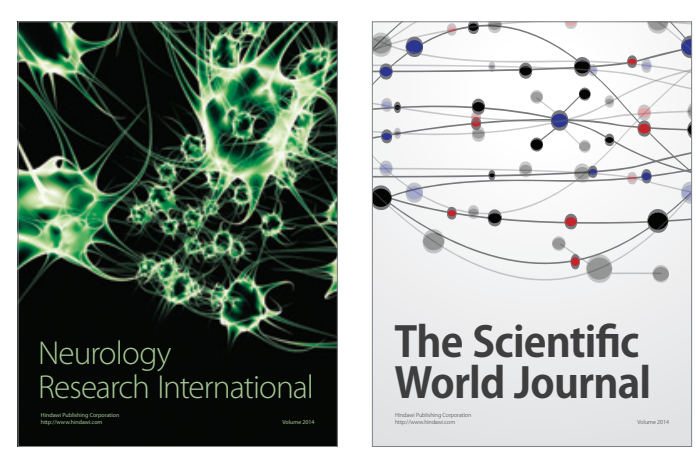

The Scientific World Journal

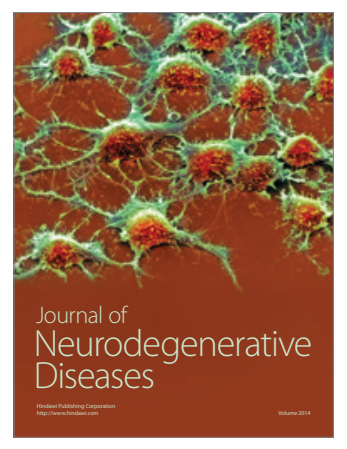

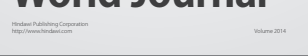

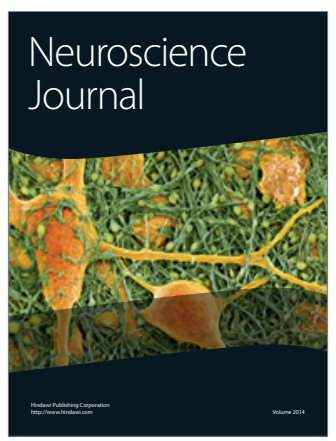

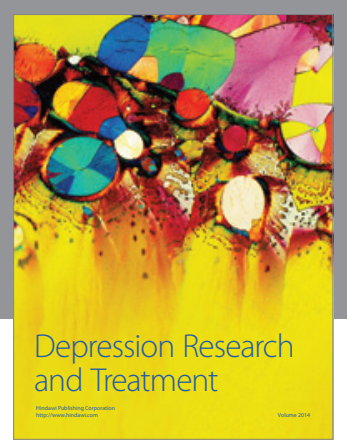
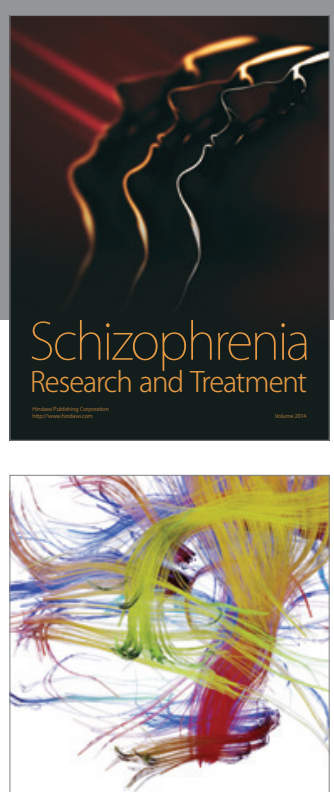

Brain Science

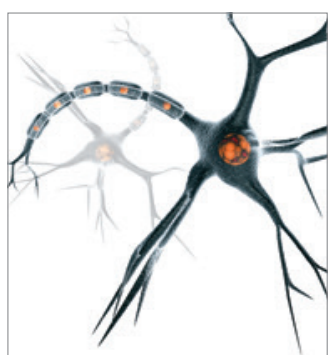

Neural Plasticity
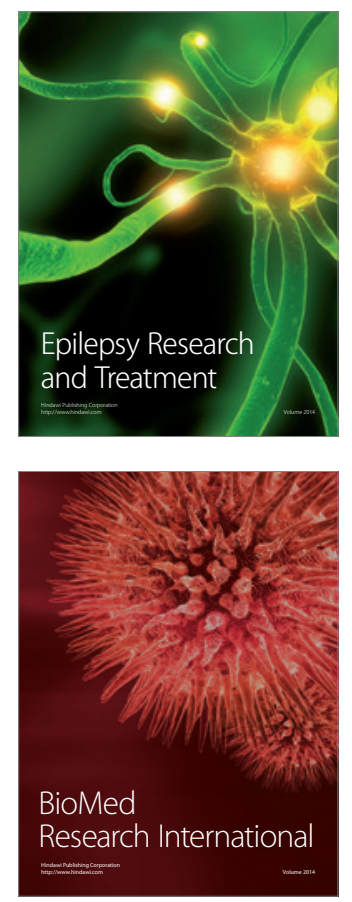

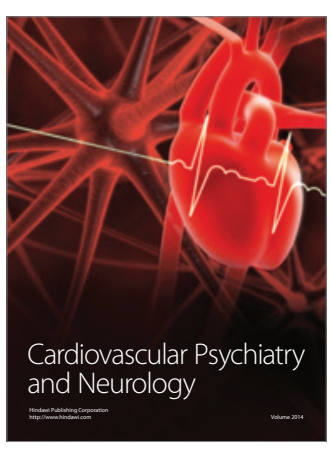

Parkinson's

Disease
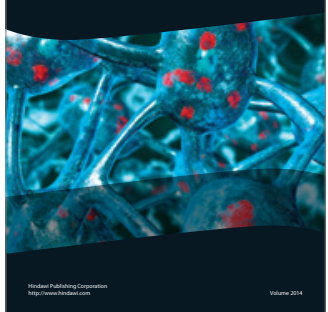